\title{
CONTROLE DE Meloidogyne javanica EM MUDAS DE BANANEIRA 'PRATA-ANÃ' POR COMPOSTOS ORGÂNICOS ${ }^{1}$
}

\author{
BRUNA HANIELLE CARNEIRO DOS SANTOS², REGINA CÁSSIA FERREIRA RIBEIRO ${ }^{3}$, \\ ADELICA APARECIDA XAVIER ${ }^{3}$, JOSÉ AUGUSTO DOS SANTOS NETO ${ }^{3}$, \\ VIRGÍLIO JAMIR GONÇALVES MOTA ${ }^{4}$
}

RESUMO - O trabalho teve como objetivo avaliar o efeito de compostos orgânicos no controle de Meloidogyne javanica, e no desenvolvimento de mudas de bananeiras 'Prata-Anã. O experimento foi conduzido em DIC, com dez repetições, e os tratamentos consistiram em quatro compostos constituídos de diferentes matérias-primas (restos da cultura da banana, cana-de-açúcar, esterco bovino, cascas de banana, plantas daninhas, capim andropogon), o esterco bovino, a torta de mamona e testemunhas (adubação mineral), carbofuran e testemunha absoluta (sem adição de composto orgânico). Em cada vaso, foram colocados 3 $\mathrm{kg}$ de solo autoclavado, incorporado com cada um dos tratamentos avaliados e inoculado com suspensão contendo 4.000 ovos de M. javanica. Após quatro dias, transplantou-se uma muda de bananeira 'Prata-Anã' micropropagada, e aos 60 dias, avaliaram-se: altura das plantas, diâmetro, número de folhas e peso de matéria seca da parte aérea, e número de galhas, massas de ovos, número de ovos e o número de juvenis de segundo estádio (J2), por $100 \mathrm{~cm}^{3}$ de solo. Testou-se in vitro o efeito das frações húmicas dos quatro compostos (que não causaram fitotoxidez) e esterco bovino sobre a mortalidade e motilidade de $\mathrm{J} 2 \mathrm{de} M$. javanica. $\mathrm{O}$ ensaio foi montado em placas de ELISA em DIC, com cinco repetições. Os compostos orgânicos e o esterco bovino aumentaram o desenvolvimento das mudas. A torta de mamona provocou efeito fitotóxico às mudas. Menor número de variáveis nematológicas foi proporcionado pela torta de mamona e pelo carbofuran. O número de J2 também foi menor nas parcelas tratadas com carbofuran e também pelo Composto 3, constituído por plantas daninhas +restos de cana-de-açúcar+ esterco bovino e pelo adubo mineral. Para o teste in vitro, as substâncias húmicas conferiram efeito nematicida e nematostático. Dentre os compostos, o C3 mostrou-se promissor por reduzir o desenvolvimento do nematoides e não apresentar efeito fitotóxico.

Termos para indexação: Nematoide das galhas, adubação orgânica, Musa spp.

\section{CONTROL OF Meloidogyne javanica ON 'PRATA- ANÃ' BANANA SEEDLINGS BY ORGANIC COMPOUNDS}

\begin{abstract}
The study aimed to evaluate the effect of organic compounds in the control of Meloidogyne javanica, and in the development of 'Prata-Anã' banana seedlings. The experiment was carried out in a completely randomized design with ten replicates, and treatments consisted of four compounds made from different raw materials (remnants of bananas crop, sugar cane, cattle manure, banana skins, weeds, Andropogon grass), the manure, the castor bean cake, and controls (mineral fertilizer; 'carbofuran' and absolute control (no added organic compounds). It was placed in each pot $3 \mathrm{~kg}$ of soil, autoclaved, mixed with each one of the treatments and inoculated with a suspension containing 4,000 eggs of M. javanica. After four days one 'Prata-Anã' micropropagated seedling was transplanted and at 60 days it was evaluated: plant height, diameter, number of leaves, dry matter weight of shoots, number of galls, egg masses, number of eggs and the number of second-stage juveniles (J2) per $100 \mathrm{~cm}^{3}$ of soil. It was tested in vitro the effect of humic fractions of the four compounds (which did not cause phytotoxicity) and cattle manure on mortality and motility of $\mathrm{J} 2$ of M. javanica. The essay was set on ELISA plates in a completely randomized design with five replications. Organic compounds and manure increased the growth of plantlets. The castor bean cake caused phytotoxic effect on the seedlings. Less number of nematological variables was provided by the castor bean cake and by the 'carbofuran'. The number of J2 was also lower in plots treated with 'carbofuran' and also by the Compound 3 constituted of weed + sugar cane residues + cattle manure and by the mineral fertilizer. For the in vitro test, the humic substances presented nematicide and nematostatic effects. Among the compounds, the $\mathrm{C} 3$ showed itself promise for reducing the development of the nematode and for not present phytotoxic effect.
\end{abstract}

Index terms: root-knot nematodes, organic manure, Musa spp.

1.(Trabalho 051-13).Trabalho 17-01-2013. Aceito para publicação: 19-0-2013.

${ }^{2}$ Engenheira Agrônoma. Mestranda do curso de Produção Vegetal no Semiárido/UNIMONTES. E-mail: Brunahcsantos@yahoo.com.br ${ }^{3}$ Eng $^{\circ}$ Agr. Dsc. Profs. Depto. Ciências Agrárias. UNIMONTES. Bolsistas da FAPEMIG. Caixa Postal 91, CEP:39440-000. JanaúbaMG.E-mails: regina.ribeiro@unimontes.br, adelica@unimontes.br, Jose.neto@unimontes

${ }^{4} \mathrm{Eng}^{\circ}$ Agr. Msc. Prof. Depto. Ciências Agrárias. UNIMONTES. C.P. 91, CEP:39440-000. Janaúba- MG. E-mail: virgilio.mota@unimontes.br 
A banana (Musa spp. L.) é uma das frutas mais consumidas no mundo e a principal destinada ao consumo in natura. O Brasil destaca-se como um dos principais produtores do mundo, com área de cultivo em todos os Estados. A região norte de Minas Gerais tem a cultura da banana como sua principal atividade agrícola, sendo a cultivar "Prata-Ana" responsável por $90 \%$ da produção. Entretanto, o potencial produtivo desta cultura na região não é totalmente expresso, em função de problemas de manejo, principalmente fitossanitários. Dentre as doenças da bananeira no Brasil, destacam-se os nematoides do gênero Meloidogyne Goeldi, com maior frequência das espécies $M$. incognita (Kofoid e White) Chitwood e M. javanica (Treub) Chitwood.. Tais nematoides podem causar em torno de $8 \%$ de perdas (COFCEWICZ et al., 2004).

A medida de controle de nematoides mais utilizada em bananais no norte de Minas é a aplicação de nematicidas. Entretanto, seu uso onera o custo de produção e contamina o meio ambiente. Assim, métodos alternativos, como a incorporação ao solo de compostos orgânicos de origem vegetal, incluindo tortas de resíduos, estercos de animais e pó de materiais vegetais de diferentes espécies de plantas vêm sendo estudados no manejo de M. javanica e M. incognita (JESSE et al., 2006; OLABIYI et al., 2007).

Dentre os principais componentes da matéria orgânica, destacam-se as substâncias húmicas, que afetam as propriedades físicas e químicas do solo, aumentando a fertilidade do solo e o desenvolvimento das plantas. As substâncias húmicas podem ser divididas em três frações: ácido fúlvico, ácido húmico e matéria húmica. Existem relatos na literatura sobre o efeito destas frações no controle de Meloidogyne spp. e Heterodera glycines Ichinohe, e no desenvolvimento de plantas (DIAS; FERRAZ, 2001; RIBEIRO et al., 2002).

No norte de Minas, região produtora de banana, alguns resíduos, a exemplo de folhas, pedúnculo, pseudocaule, engaço e casca de banana, encontram-se disponíveis em grandes quantidades. Também são encontrados torta de mamona, gramíneas, esterco animal, plantas daninhas e resíduos de cana-de-açúcar. O manejo ecologicamente aceitável de alguns destes materiais, como a casca de banana, torna-se um problema a ser resolvido. Dessa forma, uma das possíveis alternativas seria utilizá-los na agricultura, como adubo, e no controle de fitopatógenos, prática viável e de grande importância para o produtor e para o meio ambiente. No entanto, pouco ainda se conhece sobre o potencial de tais resíduos no controle de nematoides. O trabalho teve como objetivo estudar o efeito da incorporação ao solo de compostos orgânicos com diferentes materiais vegetais, no controle de $M$. javanica, em mudas de bananeira 'Prata- Anã', e avaliar o efeito de frações húmicas sobre a mortalidade e a motilidade de juvenis de M. javanica.

A compostagem dos diferentes materiais vegetais foi realizada na fazenda experimental da UNIMONTES. Os materiais vegetais utilizados foram coletados na região de Janaúba, Minas Gerais. Para a montagem das pilhas, utilizaram-se esterco bovino, casca de banana, restos da cultura da banana (engaço, pseudocaule, folhas, coração), capim andropogon, restos da cultura da cana-de-açúcar (folhas e colmos) e plantas daninhas, como malva (Malva sylvestris L.), roseta (Soliva pterosperma (Juss.) Less), carrapicho-picão (Bidens pilosa L.), jetirana (Merremia aegyptia L.), mentrasto (Ageratum conyzoides L.) e apaga-fogo (Alternanthera ficoidea (L.) P. Beauv.). Tais materiais foram triturados e umedecidos, e dispostos em camadas alternadas, gerando quatro diferentes combinações de compostos: $\mathrm{C} 1: 50 \%$ restos da cultura da banana $+25 \%$ de cana-de-açúcar $+25 \%$ esterco bovino $(\mathrm{RB}+\mathrm{CA}+\mathrm{EB})$; C2: $37,5 \%$ de cascas de banana $+37,5 \%$ de plantas daninhas $+25 \%$ de esterco bovino $(\mathrm{CB}+\mathrm{PD}+\mathrm{EB})$; C3: $50 \%$ de plantas daninhas $+25 \%$ de cana-deaçúcar $+25 \%$ de esterco bovino ( $\mathrm{PD}+\mathrm{CA}+\mathrm{EB})$, e C4: $50 \%$ de capim andropogon $+25 \%$ de cana-de-açúcar $+25 \%$ de esterco bovino $(\mathrm{CAn}+\mathrm{CA}+\mathrm{EB})$. Durante a decomposição do material orgânico, foram feitos reviramentos periódicos, umedecimento com água para aerar, homogeneizar a pilha e manter a temperatura abaixo de $65^{\circ} \mathrm{C}$.

O inóculo de $M$. javanica foi obtido de uma população pura, mantida em tomateiros cultivar 'Kada', em vasos contendo solo arenoso previamente autoclavado $120^{\circ} \mathrm{C} / 50$ minutos por três dias consecutivos). Os ovos de $M$. javanica foram extraídos das raízes de tomateiros com galhas, conforme a técnica de Hussey e Barker (1973), modificada por Bonetti e Ferraz (1981).

O ensaio foi montado em casa de vegetação da UNIMONTES e conduzido em delineamento inteiramente casualizado, com nove tratamentos e 10 repetições. A parcela experimental foi composta por um vaso contendo uma muda de banana, proveniente do Laboratorio de Micropropagação da UNIMONTES. Os tratamentos consistiram nos compostos: $\mathrm{C} 1, \mathrm{C} 2, \mathrm{C} 3, \mathrm{C} 4$, torta de mamona, esterco bovino; adubação mineral (de acordo com a análise de solo), Carbofuran (Furadan ${ }^{\circledR} 350$ SC) e testemunha absoluta (sem adição de composto orgânico). As relações $\mathrm{C} / \mathrm{N}$ dos compostos $\mathrm{C} 1, \mathrm{C} 2, \mathrm{C} 3, \mathrm{C} 4$, esterco e torta de mamona foram $15: 1 ; 19: 1 ; 18: 1 ; 25: 1 ; 10: 1$ e $7: 1$, 
respectivamente. O solo utilizado, classificado como Neossolo fúlvico (argila: $9 \mathrm{dag} / \mathrm{kg}$; areia: $86 \mathrm{dag} / \mathrm{kg}$; silte: $5 \mathrm{dag} / \mathrm{kg}$; $\mathrm{pH}: 7,1)$ foi previamente autoclavado a $120^{\circ} \mathrm{C} / 50$ minutos por três dias consecutivos. Nos tratamentos relacionados aos compostos torta de mamona e esterco, adicionaram-se $30 \mathrm{~g} / \mathrm{vaso}$, proporcional à recomendação de 20 a 30 ton/ha de compostos orgânicos na agricultura e $4 \mathrm{~mL} \mathrm{~L}^{-1}$ de água $(1,4 \mathrm{~g}$ $\mathrm{L}^{-1}$ I.A.) de carbofuran, conforme recomendação para a cultura. $\mathrm{O}$ esterco bovino utilizado foi curtido por 60 dias antes de ser utilizado.

Em sacos plásticos de $5 \mathrm{~L}$ de capacidade, foram colocados $3 \mathrm{~kg}$ de solo, mais os tratamentos e suspensão contendo 4.000 ovos de $M$. javanica. Em seguida, o saco plástico foi fechado e agitado manualmente para promover a homogeneização do solo e, então, acondicionado em vasos plásticos de $4 \mathrm{~L}$ de capacidade, e sua umidade, mantida próximo a $60 \%$ da capacidade de campo. Após quatro dias, uma muda de banana 'Prata-Anã' micropropagada foi transplantada para cada vaso. As plantas foram irrigadas de acordo com a necessidade hídrica. As avaliações foram feitas 60 dias após o plantio, sendo a altura da planta avaliada diretamente no local, com fita métrica, medindo-se do solo até a inserção da última folha completamente aberta. $\mathrm{O}$ diâmetro do pseudocaule foi determinado a $15 \mathrm{~cm}$ do solo, com auxílio de um paquímetro. O peso da matéria seca foi obtido após o corte do pseudocaule na região do colo, e secagem em estufa de circulação forçada a $65^{\circ} \mathrm{C}$, por 72 horas, até peso constante. Para a determinação das variáveis nematológicas, os sistemas radiculares das plantas foram arrancados, lavados e colorados com floxina B para contagem de galhas e massas de ovos. Em seguida, as raízes foram processadas para extração de ovos, conforme mencionado anteriormente. Os juvenis de segundo estádio (J2) no solo foram obtidos após extração de $100 \mathrm{~cm}^{3}$ do solo (JENKINS, 1964). A suspensão de ovos e de J2 foi contada em câmara de Peters, em microscópio óptico. Os resultados obtidos foram submetidos à análise de variância, e as médias, comparadas pelo teste de Scott-Knot, a 5\%, pelo programa de estatística SISVAR (FERREIRA, 2000).

Após a estabilização dos compostos, que não foram tóxicos às plantas, foram obtidas as frações ácido húmico, ácido fúlvico e matéria húmica, de acordo com a metodologia prosposta por Schnitzer (1984). Tais frações foram avaliadas quanto ao seu efeito sobre a mortalidade e motilidade de $\mathrm{J} 2$ de $M$. javanica. Para isto, em células de $300 \mu \mathrm{L}$ de placas tipo Elisa, foram colocados $20 \mu \mathrm{L}$ da suspensão contendo $20 \mathrm{~J} 2$ de $M$. javanica e $100 \mu \mathrm{L}$ de uma das frações em cada cavidade. Após 48 horas, foram contados os nematoides imóveis e mortos, conforme metodologia descrita por Chen e Dickson (2000). O ensaio foi montado em delineamento inteiramente ao acaso, com cinco repetições, em esquema fatorial $5 \times 3$, os tratamentos foram constituídos pelas três frações da matéria orgânica dos quatro compostos, e o esterco bovino, analisados no ensaio anterior. Como testemunha, utilizou-se água destilada. Os resultados obtidos foram submetidos à analise de variância, e as médias, comparadas pelo teste de médias de Scott-Knot, a 5\%, e de Dunett, a $5 \%$.

A matéria fresca de parte aérea nas plantas tratadas com os compostos $\mathrm{C} 1, \mathrm{C} 2, \mathrm{C} 3, \mathrm{C} 4$, esterco e adubo mineral foi maior que na testemunha e na torta de mamona. $\mathrm{O}$ composto 1 aumentou a matéria fresca de parte aérea em $65,77 \%$, em relação à torta de mamona. A altura das plantas foi significativamente superior nos tratamentos constituídos de compostos orgânicos, adubação mineral e esterco bovino em relação à testemunha, ao Furadan e à torta de mamona (Tabela 1). Apenas a torta de mamona e o carbofuran reduziram significativamente o diâmetro de pseudocaule, número de folhas e matéria seca de parte aérea em relação à testemunha. Vários trabalhos demonstraram que o efeito tóxico da torta de mamona foi em função da dose empregada. Martins et al. (2011) testaram a adição de diferentes doses de torta de mamona associadas a substratos comerciais na aclimatação de mudas micropropagadas de bananeira cv. Willians. Os autores verificaram que, a partir de $2 \mathrm{~g}_{\text {planta }}{ }^{-1}$, houve redução do desenvolvimento das plantas. Severino et al. (2004) também evidenciaram o efeito fitotóxico em mamoneira quando empregadas altas doses da torta. De acordo com Rodriguez-kábana et al. (1987), a torta de mamona possui baixa relação $\mathrm{C} / \mathrm{N}$ e alto conteúdo de proteína e aminoácidos. No presente trabalho, as mudas foram plantadas quatro dias após a incorporação da torta ao solo. Neste curto período de tempo, em função da baixa relação $\mathrm{C} / \mathrm{N}$ da torta de mamona $(7: 1)$, pode ter ocorrido uma rápida mineralização de nitrogênio com acúmulo de amônio e nitrato no solo, o que pode explicar o efeito fitotóxico observado e também a redução das variáveis nematológicas.

Os compostos avaliados não diferiram significativamente da testemunha, do esterco e da adubação mineral sobre o número de galhas, massas de ovos e ovos, por sistema radicular. No entanto, a torta de mamona reduziu significativamente o número de galhas, massas de ovos e ovos em 99,53\%, 99,30\% e 78,42\%, respectivamente (Tabela 2). Esta redução pode ter ocorrido em função da redução acentuada no desenvolvimento vegetativo das plantas e também devido à liberação de ricina, alcaloide tóxico 
encontrado nas sementes de mamona. De acordo com Anandan et al. (2005), a ricina encontra-se na concentração de 1,5\%-2\% e é responsável por inativar ribossomos e, por conseguinte, bloquear a síntese de outras proteínas, levando as células à morte. Segundo Rich et al. (1989), a ricina possui efeito sobre a motilidade de M. incognita. Isto pode ter ocasionado uma redução no número de nematoides que penetrou e, consequentemente, uma redução nas demais variáveis nematológicas. Com relação ao carbofuran, o resultado era esperado, visto que tal produto interfere na penetração dos nematoides nas raízes, reduzindo a atividade desses no solo e impedindo ou limitando a eclosão de juvenis (ADEGBITE; AGBAJE, 2007).

$\mathrm{O}$ composto $\mathrm{C} 3$, constituído de plantas daninhas+cana-de-açúcar+esterco bovino, foi o mais eficiente na redução de $\mathrm{J} 2$ de $M$. javanica em relação à testemunha, com diminuição de 37,22\% (Tabela 2). Algumas plantas daninhas apresentam substâncias químicas, como flavonoides, saponinas, amidas, incluindo benzamida e cetonas, que, isoladamente ou em combinação, apresentam efeito nematicida, inibindo a eclosão e conferindo mortalidade aos nematoides (ADEGBITE; ADESIYAN, 2005,). Maior número de $\mathrm{J} 2$ por $100 \mathrm{~cm}^{3}$ de solo foi verificado no solo, ao qual se incorporou a torta de mamona (Tabela 2). Resultados semelhantes foram obtidos por Nandal e Bhatti (1987) que, ao adicionarem ao solo extratos de folhas de mamona para o cultivo de berinjela, observaram ao final de 60 dias aumento no número de galhas e na eclosão de juvenis. Os autores sugerem que isto pode ter ocorrido devido à decomposição do componente tóxico. De acordo com Brito e Chierice (2011), a ricina é um composto bastante solúvel em água e, assim, em solos arenosos, apresenta alta mobilidade. Isto pode explicar o número elevado de juvenis do nematoide.

A utilização de esterco bovino não foi eficiente no controle de $M$. javanica. Estes resultados discordam dos observados por Alves et al. (2007), que verificaram que diferentes proporções de esterco de curral no solo aumentaram a concentração de fenóis nas raízes de tomateiro, o que foi deletério às células gigantes e prejudicial ao desenvolvimento do nematoide.

Houve interação significativa entre os compostos e as frações húmicas sobre a mortalidade de J2 de $M$. javanica. Nos compostos e no esterco bovino, a fração ácido húmico $(\mathrm{AH})$ causou maior mortalidade em relação ao ácido fúlvico e à matéria húmica (Tabela 3), conferindo mortalidade de $\mathrm{J} 2$ de $M$. javanica acima de $90 \%$. Considerando o efeito das frações, verifica-se que o ácido fúlvico de todos os compostos causou mortalidade acima de $90 \%$, diferindo da testemunha.

$\mathrm{O}$ composto $\mathrm{C} 3$ e o esterco foram os que causaram maior mortalidade de nematoides (Tabela 3). Com relação à motilidade de $\mathrm{J} 2$ de $M$. javanica, também se verificou efeito significativo da interação entre frações e compostos. A fração ácido fúlvico dos compostos $\mathrm{C} 3$ e $\mathrm{C} 2$ foi a que causou maior imobilidade dos nematoides, demonstrando efeito nematostático (Tabela 4). No composto C2, maior imobilidade dos juvenis ocorreu com o ácido húmico. Não existem trabalhos na literatura demonstrando o efeito individual de frações húmicas sobre a mortalidade e a mobilidade de nematoides. Já com relação à eclosão de juvenis, que não foi avaliada no trabalho, Kesba e Al-Shalaby (2008) testaram vários produtos comerciais à base de ácido húmico e verificaram redução da eclosão de $M$. incognita. Segundo Tan (1977), as frações húmicas possuem efeito inibitório à microrganismos, principalmente $\mathrm{o}$ ácido húmico, substância com alto peso molecular, constituindo uma fração complexa, estável e de difícil metabolização.

Diante dos resultados obtidos, pode-se ressaltar que susbtâncias húmicas, tais como ácidos húmicos, ácidos fulvicos presentes nos compostos avaliados e no esterco bovino, apresentaram efeito nematicida e nematostático, in vitro, e os compostos promoveram maior peso de matéria fresca de parte aérea e maior altura de mudas em relação à testemunha. $\mathrm{O}$ composto $\mathrm{C} 3$ reduz o número de juvenis de segundo estádio de $M$. javanica e não afetou o desenvolvimento das mudas, a torta de mamona apresenta efeito tóxico para as mudas de bananeira 'Prata-Anã'. Maior atividade nematicida ao $M$. javanica foi proporcionada pelos ácidos húmico e fúlvico dos compostos $\mathrm{C} 2, \mathrm{C} 3$ e do esterco bovino, e o ácido húmico de todos compostos apresentou maior atividade nematicida.

Os autores agradecem à Fundação de Amparo à Pesquisa do Estado de Minas Gerais - FAPEMIG, pela concessão da Bolsa de Incentivo à Pesquisa e ao Desenvolvimento Tecnológico - BIPDT . 
TABELA 1 - Diâmetro do pseudocaule (DP), número de folhas (NF), peso da matéria seca da parte aérea (MSPA), peso de matéria fresca de parte aérea (MFPA) e altura de mudas de bananeira 'Prata-Anã' cultivadas em solo contendo compostos orgânicos, adubo mineral e carbofuran.

\begin{tabular}{lccccc}
\hline Tratamento & DP $(\mathrm{cm})$ & NF & MSPA $(\mathrm{g})$ & MFPA $(\mathrm{g})$ & Altura $(\mathrm{cm})$ \\
\hline Composto 1 & $2,00 \mathrm{a}$ & $7,6 \mathrm{a}$ & $12,10 \mathrm{a}$ & $62,2 \mathrm{a}$ & $19,90 \mathrm{a}$ \\
Composto 2 & $2,00 \mathrm{a}$ & $8,1 \mathrm{a}$ & $12,10 \mathrm{a}$ & $64,5 \mathrm{a}$ & $20,90 \mathrm{a}$ \\
Composto 3 & $2,00 \mathrm{a}$ & $8,0 \mathrm{a}$ & $12,20 \mathrm{a}$ & $57,6 \mathrm{a}$ & $20,30 \mathrm{a}$ \\
Composto 4 & $2,00 \mathrm{a}$ & $7,5 \mathrm{a}$ & $11,00 \mathrm{a}$ & $58,5 \mathrm{a}$ & $19,50 \mathrm{a}$ \\
Esterco Bovino & $2,00 \mathrm{a}$ & $7,6 \mathrm{a}$ & $8,60 \mathrm{a}$ & $56,0 \mathrm{a}$ & $19,10 \mathrm{a}$ \\
Torta de Mamona & $1,20 \mathrm{c}$ & $5,7 \mathrm{~b}$ & $2,10 \mathrm{c}$ & $21,6 \mathrm{c}$ & $11,60 \mathrm{c}$ \\
Adubação Mineral (4:14:8) & $1,80 \mathrm{a}$ & $8,2 \mathrm{a}$ & $9,50 \mathrm{a}$ & $56,0 \mathrm{a}$ & $20,40 \mathrm{a}$ \\
Carbofuran & $1,50 \mathrm{~b}$ & $5,8 \mathrm{~b}$ & $6,50 \mathrm{~b}$ & $34,3 \mathrm{~b}$ & $15,20 \mathrm{~b}$ \\
Testemunha & $1,80 \mathrm{a}$ & $7,4 \mathrm{a}$ & $8,40 \mathrm{a}$ & $33.0 \mathrm{~b}$ & $16,10 \mathrm{~b}$ \\
\hline CV $\%)$ & 15,40 & 12,92 & 21,31 & 24,5 & 13,61 \\
\hline
\end{tabular}

*Médias seguidas pela mesma letra não diferem significativamente entre si, pelo teste Scott-Knott, a 5\%.

$\mathrm{C} 1(\mathrm{RB}=$ restos da cultura da banana; $\mathrm{CA}=$ cana-de-açúcar; $\mathrm{EB}=$ Esterco bovino $)$

$\mathrm{C} 2(\mathrm{CB}=$ casca de banana; $\mathrm{PD}=$ plantas daninhas; $\mathrm{EB}=$ Esterco bovino $)$

$\mathrm{C} 3(\mathrm{PD}=$ plantas daninhas; $\mathrm{CA}=$ cana-de-açúcar; $\mathrm{EB}=$ Esterco bovino)

$\mathrm{C} 4(\mathrm{CAn}=$ capim angropogon; $\mathrm{CA}=$ cana-de-açúcar;EB= Esterco bovino)

TABELA 2 - Número de galhas, massas de ovos e ovos de Meloidogyne javanica por sistema radicular de bananeira Prata- Anã e de juvenis no solo, dois meses após o cultivo em solo contendo compostos orgânicos, adubo mineral e carbofuran.

\begin{tabular}{lcccc}
\hline Tratamento & Galhas & Massas & Ovos & $\mathrm{J} 2$ \\
\hline Torta de Mamona & $0,50 \mathrm{a}$ & $0,30 \mathrm{a}$ & $2059,40 \mathrm{a}$ & $591,60 \mathrm{c}$ \\
Furadan & $10,30 \mathrm{a}$ & $3,50 \mathrm{a}$ & $900,80 \mathrm{a}$ & $55,10 \mathrm{~b}$ \\
Composto 3 & $59,50 \mathrm{~b}$ & $35,90 \mathrm{~b}$ & $6113,50 \mathrm{~b}$ & $135,60 \mathrm{~b}$ \\
Adubação Mineral & $76,60 \mathrm{~b}$ & $51,70 \mathrm{~b}$ & $8580,00 \mathrm{~b}$ & $155,70 \mathrm{~b}$ \\
Composto 4 & $82,30 \mathrm{~b}$ & $45,50 \mathrm{~b}$ & $8119,90 \mathrm{~b}$ & $240,00 \mathrm{a}$ \\
Esterco & $86,40 \mathrm{~b}$ & $37,50 \mathrm{~b}$ & $7681,90 \mathrm{~b}$ & $218,80 \mathrm{a}$ \\
Composto 1 & $92,40 \mathrm{~b}$ & $59,30 \mathrm{~b}$ & $6421,80 \mathrm{~b}$ & $206,40 \mathrm{a}$ \\
Composto 2 & $106,00 \mathrm{~b}$ & $52,30 \mathrm{~b}$ & $8308,60 \mathrm{~b}$ & $221,50 \mathrm{a}$ \\
Testemunha & $106,50 \mathrm{~b}$ & $43,30 \mathrm{~b}$ & $9545,60 \mathrm{~b}$ & $216,00 \mathrm{a}$ \\
\hline CV $(\%)$ & 31,15 & 39,53 & 26,83 & \\
\hline
\end{tabular}

Para análise estatística, os dados foram transformados em $\sqrt{\mathrm{x}+0,5}$. Médias seguidas pela mesma letra não diferem significativamente entre si, pelo teste Scott-Knott, a $5 \%$.

$\mathrm{C} 1(\mathrm{RB}=$ restos da cultura da banana; $\mathrm{CA}=$ cana-de-açúcar; $\mathrm{EB}=$ Esterco bovino $)$

$\mathrm{C} 2(\mathrm{CB}=$ casca de banana; $\mathrm{PD}=$ plantas daninhas; $\mathrm{EB}=$ Esterco bovino $)$

$\mathrm{C} 3(\mathrm{PD}=$ plantas daninhas; $\mathrm{CA}=$ cana-de-açúcar; $\mathrm{EB}=$ Esterco bovino)

$\mathrm{C} 4$ ( $\mathrm{CAn}=$ capim angropogon; $\mathrm{CA}=$ cana-de-açúcar; $\mathrm{EB}=$ Esterco bovino)

TABELA 3 - Porcentagem de mortalidade de Meloidogyne javanica submetidos a diferentes frações de compostos e esterco bovino, in vitro.

\begin{tabular}{lccc}
\multirow{2}{*}{ Compostos } & \multicolumn{3}{c}{ Frações } \\
\cline { 2 - 4 } & Ácido Fúlvico & Ácido Húmico & Matéria Húmica \\
\hline $\mathrm{C} 4(\mathrm{CAn}+\mathrm{CA}+\mathrm{EB})$ & $0,00 \mathrm{aA}$ & $94,06 \mathrm{bB}^{*}$ & $0,00 \mathrm{aA}$ \\
$\mathrm{C} 1(\mathrm{RB}+\mathrm{CA}+\mathrm{EB})$ & $10,46 \mathrm{aA}$ & $98,00 \mathrm{bB}^{*}$ & $3,33 \mathrm{aA}$ \\
$\mathrm{C} 2(\mathrm{CB}+\mathrm{PD}+\mathrm{EB})$ & $61,06 \mathrm{bB}^{*}$ & $71,44 \mathrm{cA}$ & $3,81 \mathrm{aA}$ \\
$\mathrm{C} 3(\mathrm{PD}+\mathrm{CA}+\mathrm{EB})$ & $76,75 \mathrm{bB}^{*}$ & $97,46 \mathrm{cB}^{*}$ & $1,33 \mathrm{aA}$ \\
Esterco bovino & $86,49 \mathrm{bB}^{*}$ & $100,00 \mathrm{cB}^{*}$ & $0,00 \mathrm{aA}$ \\
\hline $\mathrm{H}_{2} \mathrm{O}$ & 0,00 & 0,00 & 0,00 \\
\hline
\end{tabular}

Médias següidas de mesma letra maiúscula na coluna e minúscula na linha não diferem estatisticamente entre si, pelo teste de ScottKnott, a 5\%. *Teste de Dunett a 5\%.

$\mathrm{C} 1(\mathrm{RB}=$ restos da cultura da banana; $\mathrm{CA}=$ cana-de-açúcar; $\mathrm{EB}=$ Esterco bovino $)$

$\mathrm{C} 2(\mathrm{CB}=$ casca de banana; $\mathrm{PD}=$ plantas daninhas; $\mathrm{EB}=$ Esterco bovino $)$

$\mathrm{C} 3(\mathrm{PD}=$ plantas daninhas; $\mathrm{CA}=$ cana-de-açúcar; $\mathrm{EB}=$ Esterco bovino $)$

$\mathrm{C} 4(\mathrm{CAn}=$ capim angropogon; $\mathrm{CA}=$ cana-de-açúcar; $\mathrm{EB}=$ Esterco bovino) 
TABELA 4 - Porcentagem de juvenis Meloidogyne javanica imóveis submetidos a diferentes frações de compostos e esterco bovino, in vitro.

\begin{tabular}{cccr}
\hline \multirow{2}{*}{ Compostos } & \multicolumn{3}{c}{ Frações } \\
\cline { 2 - 4 } & Ácido Fúlvico & Ácido Húmico & Matéria Húmica \\
\hline $\mathrm{C} 4(\mathrm{CAn}+\mathrm{CA}+\mathrm{EB})$ & $7,49 \mathrm{aA}$ & $5,99 \mathrm{aA}$ & $11,30 \mathrm{aA}$ \\
Esterco bovino & $13,51 \mathrm{aB}$ & $0,00 \mathrm{aA}$ & $21,97 \mathrm{aB}$ \\
$\mathrm{C} 1(\mathrm{RB}+\mathrm{CA}+\mathrm{EB})$ & $13,81 \mathrm{aA}$ & $2,00 \mathrm{aA}$ & $15,00 \mathrm{aA}$ \\
$\mathrm{C} 3(\mathrm{PD}+\mathrm{CA}+\mathrm{EB})$ & $23,25 \mathrm{aB}$ & $2,53 \mathrm{aA}$ & $0,00 \mathrm{aA}$ \\
$\mathrm{C} 2(\mathrm{CB}+\mathrm{PD}+\mathrm{EB})$ & $38,94 \mathrm{bB} *$ & $12,76 \mathrm{aA}$ & $12,77 \mathrm{aA}$ \\
\hline $\mathrm{H}_{2} \mathrm{O}$ & 0,00 & 0,00 & 0,00 \\
\hline
\end{tabular}

Médias seguidas de mesma letra maiúscula na coluna e minúscula na linha não diferem estatisticamente entre si, pelo teste de ScottKnott, a $5 \%$. *Teste de Dunett a 5\%.

$\mathrm{C} 1(\mathrm{RB}=$ restos da cultura da banana; $\mathrm{CA}=$ cana-de-açúcar; $\mathrm{EB}=$ Esterco bovino)

$\mathrm{C} 2(\mathrm{CB}=$ casca de banana; $\mathrm{PD}=$ plantas daninhas; $\mathrm{EB}=$ Esterco bovino $)$

$\mathrm{C} 3(\mathrm{PD}=$ plantas daninhas; $\mathrm{CA}=$ cana-de-açúcar; $\mathrm{EB}=$ Esterco bovino)

$\mathrm{C} 4$ ( $\mathrm{CAn}=$ capim angropogon; $\mathrm{CA}=$ cana-de-açúcar; $\mathrm{EB}=$ Esterco bovino $)$

\section{REFERÊNCIAS}

ADEGBITE, A.A.; ADESIYAN, S.O. Root extracts of plants to control root-knot nematode on edible soybean. World Journal of Agricultural Sciences, Paquistão, v.1, n.1, p.18-21, 2005.

ADEGBite, A.A.; AGBAJE, G.O. Efficacy of furadan (carbofuran) in control of root-knot nematode (Meloidogyne incognita race 2) in hybrid yam varieties in southwestern Nigeria. Electronic Journal of Environmental, Agricultural and Food Chemistry, Ourense, v. 6, n. 6, p. 2083-2094, 2007.

ALVES, F.R.; FREITAS, L.G.; MARTINELLI, P.R.P.; MEIRA, R.M.S.A.; FERRAZ ,S.; DEMUNER, A.J.; BORGES, E.E.L.; JESUS JÚNIOR, W.C. Efeitos de diferentes níveis de material orgânica no solo e de inóculo sobre a interação planta - Meloidogyne spp. e a produção massal de Pasteuria penetrans. Summa Phytopathologica, Botucatu, v.33, n.4, p. 397-401, 2007.

ANANDAN, A.; KUMAR, G. K. A.; GHOSH, J.; RAMACHANDRA, K. S. Effect of different physical and chemical treatments on detoxification of ricin in castor cake. Animal Feed Science and Technology, Amsterdam, v.120, p.159-168, 2005.

BONETI, J.I.S.; FERRAZ, S. Modificação do método de Hussey e Barker para extração de ovos de Meloidogyne exigua de cafeeiro. Fitopatologia Brasileira, Brasília, v. 6, p. 553, 1981.
BRITO, N. M.; CHIERICE, G. O. Estudo da mobilidade de ricina e ricinina provenientes de torta de mamona (Ricinus communis) empregada como fertilizante de solos. Acta Tecnológica, São Luis, v. 6, n. 2, p. 60-63, 2011.

CHEN, S.Y.; DICKSON, D.W. A technique for determining live second-stage juveniles of Heterodera glycines. Journal of Nematology, Hanover, v. 32, n. 1, p. 117-121, 2000.

COFCEWICZ, E. T.; CARNEIRO, R. M. D. G.; CASTAGNONE-SERENO, P.; QUÉNEHERVÉ, P. Enzyme phenotype and genetic diversity of root-knot nematodes parasiting Musa in Brazil. Nematology, Leiden, v. 6, n. 1, p. 85-95, 2004.

DIAS, C.R.; FERRAZ, S. Efeito de frações biodigeridas de esterco de galinha sobre a eclosão e a mortalidade de juvenis Heterodera glyceines. Nematologia Brasileira, Piracicaba v.25, n. 1, p.99-101, 2001.

FERREIRA, D. F. Análises estatísticas por meio do Sisvar para Windows versão 4.0. In: REUNIÃO ANUAL DA REGIÃO BRASILEIRA DA SOCIEDADE INTERNACIONAL DE BIOMETRIA, 45., 2000, São Carlos. Anais... São Carlos: UFSCAR, 2000. p. 255-258.

JENKINS, W. R. A rapid centrifugal-flotation technique for separating nematodes from soil. Plant Disease Reporter, Saint Paul, v. 48, p. 692, 1964. 
JESSE, Y. A.; SULE, H.; PHILIP, C. B. Doruwa (Parkia biglobosa) fruit husk and hyptis (Hyptis spicigera) leaves for controlling root-knot nematodes (Meloidogyne incognita) in tomato (Lycopersicon esculentum Mill C. V.). Journal of Tropical Agriculture, New Delhi, v. 44, n. 1-2, p. 83-85, 2006.

KESBA, H. H.; AL-SHALABY, M. E. M. Survival and reproduction of Meloidogyne incognita on tomato as affected by humic acid. Nematology, Leiden, v. 10, n. 2, p. 243-247, 2008.

MARTINS, A.N.; SUGUINO, E.; DIAS, N. M. S.; PERDONÁ, M. J. Adição de torta de mamona em substratos na aclimatação de mudas micropropagadas. Revista Brasileira de Fruticultura, Jaboticabal, v. 33, n. 1, p. 198-207, 2011.

NANDAL, S. N.; BHATTIHATTI, D. S. Effect of some weed and shrub extracts on penetration and gall formation by Meloidogyne javanica on brinjal. Nematologia Mediterranea, Bari, v. 15, n. 1/2, p. 159-162, 1987.

OLABIYI, T. I.; AKANBI, W. B.; ADEPOJU, I. O. Control of certain nematode pests with different organic manure on cowpea. American-Eurasian Journal of Agricultural and Environmental Science, Cairo, v. 2, n. 5, p. 523-527. 2007.
RIBEIRO, R.C.F.; DIAS, C. R.; EZEQUIEL, D. P.; FERRAZ, S. Efeito de frações de esterco de galinha na eclosão de juvenis de segundo stádio de Meloidogyne exigua. Nematologia Brasileira, Piracicaba, v.26, n. 2, p. 231-235. 2002.

RICH, J.R.; RAHI, G.S.; OPPERMAN, C.H.; DAVIS, E.L. Influence of the castor bean (Ricinus communis) lectin (ricin) on motility of Meloidogyne incognita. Nematropica, DeLeon, v. 19, n. 1, p. 99-103, 1989.

RODRÍGUEZ-KÁBANA R; MORGAN-JONES, G; CHET, I. Biological control of nematodes: soil amendments and microbial antagonists. Plant and Soil, Dordrecht, v. 100, p. 237-247, 1987.

SCHNITZER, M. Methodos of soil analysis. Madison: American Society of Agronomy. 1984. v.2, p. 581-594.

SEVERINO, L.S.; COSTA, F.X.; BELTRÃO, N.E.M.; LUCENA, A.M.A.; GUIMARÃES, M.M.B. Mineralização da torta de mamona, esterco bovino e bagaço de cana estimada pela respiração microbiana. Revista de Biologia e Ciências da Terra, Campina Grande, v. 5, n.1, 2004.

TAN, K.H. High and low molecular wheight fractions of humic and fulvic acids. Plant and Soil, Dordrecht, v.48, p.89-101. 1977. 